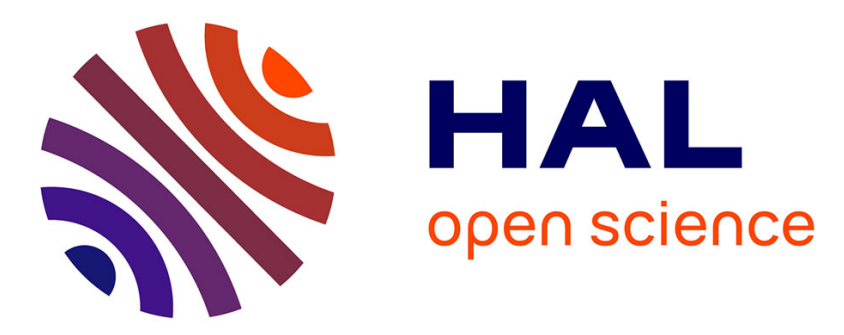

\title{
A new method to measure allyl isothiocyanate (AITC) concentrations in mustard: comparison of AITC and commercial mustard solutions as earthworm extractants
} Céline Pélosi, François Chiron, Florence Dubs, Mickael Hedde, Jean-François Ponge, Sandrine Salmon, Daniel Cluzeau, Sylvie Nelieu

\section{To cite this version:}

Céline Pélosi, François Chiron, Florence Dubs, Mickael Hedde, Jean-François Ponge, et al.. A new method to measure allyl isothiocyanate (AITC) concentrations in mustard: comparison of AITC and commercial mustard solutions as earthworm extractants. Applied Soil Ecology, 2014, 80, pp.1-5. 10.1016/j.apsoil.2014.03.005 . hal-00981416

\author{
HAL Id: hal-00981416 \\ https://hal.science/hal-00981416
}

Submitted on 23 Apr 2014

HAL is a multi-disciplinary open access archive for the deposit and dissemination of scientific research documents, whether they are published or not. The documents may come from teaching and research institutions in France or abroad, or from public or private research centers.
L'archive ouverte pluridisciplinaire HAL, est destinée au dépôt et à la diffusion de documents scientifiques de niveau recherche, publiés ou non, émanant des établissements d'enseignement et de recherche français ou étrangers, des laboratoires publics ou privés. 
1 A new method to measure allyl isothiocyanate (AITC) concentrations in mustard -

2 Comparison of AITC and commercial mustard solutions as earthworm extractants

3

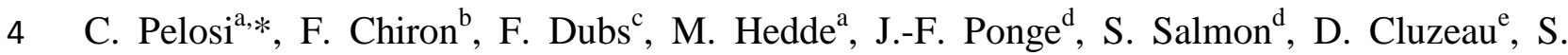
5 Nélieu $^{\mathrm{a}}$

6

7

8

9

\section{9}

${ }^{a}$ INRA, UR251 Pessac, 78026 Versailles cedex, France

${ }^{\text {b } U n i v e r s i t e ́ ~ P a r i s ~ S u d, ~ U M R ~} 8079$ Ecologie Systématique Evolution, 91405 Orsay, France

${ }^{\mathrm{c}}$ IRD, UMR BIOEMCO, Centre France Nord, 93143 Bondy Cedex, France

d Muséum National d'Histoire Naturelle, CNRS UMR 7179, 4 Avenue du Petit-Château, 91800 Brunoy, France

${ }^{\mathrm{e}}$ Université de Rennes 1, CNRS UMR6553 EcoBio, Station Biologique, 35380 Paimpont, France

* Corresponding author: UR 251 PESSAC INRA, Bâtiment 6, RD 10, 78026 Versailles cedex, France. Tel: (+33)1.30.83.36.07; Fax: (+33)1.30.83.32.59. E-mail address: celine.pelosi@versailles.inra.fr

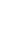
0 
27 - A new method is proposed to measure allyl isothiocyanate concentration in mustard

28 - AITC concentration in mustard varied five-fold, depending on its use by date

29 - AITC concentration was about 4 times higher in the AITC solution than in the mustard one

30 - AITC and commercial mustard solutions had the same earthworm extracting efficiency 


\section{Abstract}

Earthworms are target organisms both for scientists studying the biological component of soils and for farmers concerned with monitoring the quality of their soils. Different expellants are used to extract earthworms from the soil but differences in chemical properties and efficiency between commercial mustard and allyl isothiocyanate (AITC) solutions remain unknown. The objectives of this study were to compare $(i)$ the concentration of irritating product (allyl isothiocyanate AITC) in two expellant solutions (diluted mustard or AITC solution) and (ii) their efficiency in extracting earthworms from the soil.

AITC concentration was analyzed according to a new method, based on AITC solvent extraction and HPLC quantification, in one commercial mustard brand to assess its variability within and between batches of jars. According to mustard spiking with AITC standard solution, extraction recovery was estimated as $98 \pm 2 \%$. Earthworm field data were collected in spring 2012 in 22 cultivated fields located in east Î le-de-France, comparing pure AITC to commercial mustard solutions. Species diversity, abundance and biomass of earthworms per plot were measured.

We showed that AITC concentration in commercial mustard varied according to the use by date but not according to the batch. We thus recommend using the freshest mustard available from the same batch. Moreover, AITC solution was found to be about four times more concentrated in AITC than the commercial mustard solution. Despite this result, no significant differences were found in the efficiency of commercial mustard or AITC solutions to bring earthworms to the soil surface in terms of abundance, biomass or diversity. We thus discuss the advantage and drawbacks of using both expellants in the field.

Keywords: Earthworm sampling; Efficiency; Chemical extraction; Expellant. 


\section{Introduction}

Earthworms exert important agro-ecological functions (e.g. they influence organic matter dynamics and soil structure; Edwards and Bohlen, 1996; Sims and Gerard, 1999) and are recognized as good biological indicators of soil quality and impacts of cultural practices (Oberholzer et al., 2012; Paoletti, 1999). These organisms are interesting, both for scientists studying the biological component of cultivated soils and for farmers concerned with monitoring the quality of their soils and assessing the effects of different cultural practices. The common interest of all these people is to move towards sustainable agriculture, producing enough yields while limiting environmental damage.

In order to assess human impacts on soil biodiversity and soil invertebrate biomass, earthworms have been sampled by scientists for several decades (Evans and Guild, 1948) and more and more by the general public using standardized and simplified protocols (http://aceracre.ca/wp-content/uploads/2011/09/EMAN-MONITORING-BIODIVERSITY-IN-

CANADIAN-FORESTS.pdf; http://ecobiosoil.univ-rennes1.fr/OPVT_accueil.php; http://observatoire-agricolebiodiversite.fr/sites/oab.mnhn.fr/files/upload/attached/oab_guide_utilisateur_2013_protocolevers-de-terre.pdf; http://www.opalexplorenature.org/soilsurvey).

Different 'scientific methods' are used (Valckx et al., 2011). A common one consists of combining the application of a chemical expellant, which brings earthworms to the soil surface with hand-sorting of the underlying soil (Bartlett et al., 2010). Various chemicals can be used, like formalin (ISO 23611-1:2006; Raw, 1959), mustard powder (Högger, 1993; Muramoto and Werner, 2002) or different brands of commercial mustard (Lawrence and Bowers, 2002; Pelosi et al., 2009). More recently, researchers have demonstrated the effectiveness of allyl isothiocyanate (AITC), an irritating molecule contained in commercial mustard, for sampling earthworms in cultivated areas (Pelosi et al., 2009; Zaborski, 2003). 
Moreover, according to Čoja et al. (2008), while formalin may harm soil organisms, AITC has no undesirable side-effects on soil organisms.

In France, the participatory method of earthworm sampling consists of the application of commercial hot mustard Amora ${ }^{\circledR}$ 'Fine et Forte' solution on the soil (http://observatoireagricole-

biodiversite.fr/sites/oab.mnhn.fr/files/upload/attached/oab_guide_utilisateur_2013_protocolevers-de-terre.pdf). However, due to commercial confidentiality, the concentration of AITC in this mustard is unknown, as for all other mustard brands used for earthworm sampling. To date, no study has compared the chemical properties of commercial mustard and AITC. The objectives of the present work are to compare (i) the irritating properties of two chemicals used for sampling earthworms and (ii) the efficiency of the two expellant solutions in terms of diversity, abundance and biomass of earthworms.

\section{Materials and Methods}

\subsection{Chemical analysis of commercial hot mustard}

\subsubsection{Commercial hot mustard and chemicals}

AITC concentration was analyzed in the commercial mustard Amora ${ }^{\circledR}$ 'Fine et Forte'. To assess variability in AITC concentration, ten $150 \mathrm{~g}$ jars from different batches and ten 150 $\mathrm{g}$ jars from the same batch were compared. AITC (synthetic grade, estimated 97.3\%) was purchased from VWR and acetonitrile (HPLC-plus grade) from Carlo-Erba. LC-grade water (resistivity > $18.2 \mathrm{MOhm} \mathrm{cm}$ ) was produced by a Maxima system (USF Elga, High Wycombe, UK).

\subsubsection{Extraction procedure}


To our knowledge, only one method has been published to measure AITC in mustard (Hils et al., 2001). This method uses water vapor distillation into an ammonia-holding receiver, the allyl thiourea from the AITC then being measured by spectrophotometry. It thus requires a specific distillation apparatus and allows quantification of a transformation product, but not AITC itself. We thus chose to develop a new method, based on AITC solvent extraction and HPLC quantification. According to the optimized method, $2.5 \mathrm{~g}$ of mustard were weighed in a $50 \mathrm{~mL}$ polypropylene tube (Falcon BD) and immediately suspended in 5 $\mathrm{mL}$ LC-grade water. Then, $7.5 \mathrm{~mL}$ of acetonitrile were added and the mixture was agitated for $10 \mathrm{~min}$ on an orbital shaker at $300 \mathrm{rpm}$ (KS501 digital, Ika), sonicated for $30 \mathrm{~min}$ at a temperature below $30{ }^{\circ} \mathrm{C}$ and centrifuged (Allegra X-15R, Beckman Coulter) for 10 min at $1300 \mathrm{~g}$ and $20{ }^{\circ} \mathrm{C}$. The supernatant was removed with a Pasteur pipette and collected in a 50 $\mathrm{mL}$ glass vial with a screw cap with PTFE coated seal and protected from light. The sample was extracted three times consecutively with water and acetonitrile as described above and all extracts were collected in the same vial. The final volume $(35-37 \mathrm{~mL})$ was estimated by weighing, the extract density being estimated at 0.871 . A $2 \mathrm{~mL}$ aliquot was filtered with 0.45 $\mu \mathrm{m}$ hydrophilic PTFE filter (4 mm, Millex-LH, Millipore) prior to HPLC-UV analysis, collecting filtrate from the fifteenth droplet into the HPLC-injection vial. According to mustard spiking with AITC standard solution, extraction recovery was estimated as $98 \pm 2 \%$ (approximately $77 \%, 17 \%$ and $4 \%$ at each successive extraction cycle).

\subsubsection{HPLC-UV analysis}

HPLC-UV analyses were performed on a Dionex system, including an ASI100T autosampler, a P580 pump, a STH585 column oven and a UVD380S UV-photodiode array detector. Separation was done on a 125 x 2 mm $3 \mu$ m Nucleodur C18 HTec reversed-phase column (Macherey-Nagel ${ }^{\circledR}$, Düren, Germany) at $20{ }^{\circ} \mathrm{C}$, using a gradient of water and 
acetonitrile at $0.3 \mathrm{~mL} \mathrm{~min}{ }^{-1}$ flow rate (75/25 to $25 / 75 \mathrm{v} / \mathrm{v}$ in $\left.20 \mathrm{~min}\right)$. Samples were kept at 15 ${ }^{\circ} \mathrm{C}$ and protected from light in the autosampler before being injected. The injection volume was $5 \mu \mathrm{L}$. Quantifications were carried out at $242 \mathrm{~nm}$ using external calibration. The limit of quantification was estimated at ca. $14 \mu \mathrm{g} \cdot \mathrm{g}^{-1}$ and the linear range was above $2800 \mu \mathrm{g} \cdot \mathrm{g}^{-1}$ (AITC/mustard). All analyzed mustard jars were extracted and analyzed in triplicate, with a standard deviation of less than $6 \%$.

\subsection{Earthworm sampling}

\subsubsection{Sites and crop systems}

Field data were collected in spring 2012 in 22 cultivated fields located in Seine-etMarne, east of Île-de-France. Among them, 11 fields were under conventional farming and 11 under organic farming. Soils were clay loamy (70\% silt, $25 \%$ clay and 5\% sand on average) at near-neutral pH (Appendix A).

The climate was temperate oceanic, with a mean annual rainfall of $640 \mathrm{~mm}$ and a mean annual temperature of $10.4{ }^{\circ} \mathrm{C}$.

Conventional plowing at $25-30 \mathrm{~cm}$ depth was carried out in all fields, at a frequency ranging from every year to once every three years. The last plowing was done in 2010 or 2011, depending on the field. All fields were cultivated with winter wheat at the time of sampling. Samplings with AITC and commercial mustard were done on the same fields and on the same days.

\subsubsection{Samplings with AITC}

We use the procedure proposed by Pelosi et al., 2009 for AITC application. First, AITC was diluted with isopropanol (propan-2-ol, RPE grade, Carlo-Erba) to obtain a 5 g.L L $^{-1}$ solution (Pelosi et al., 2009; Zaborski, 2003). This solution was then diluted with water to 
reach a concentration of 0.1 g. $\mathrm{L}^{-1}$. After removing vegetation present at the ground surface, two applications of $3.2 \mathrm{~L}$ of the prepared AITC solution were applied to the soil at 10-min interval within a 40 x $40 \mathrm{~cm}$ metal frame. Taking into account the sample area, a jug with a spout has been used for the application of the AITC solution since a watering can with a rose would not have been appropriate. Emerging individuals were collected for $20 \mathrm{~min}$ and preserved in 4\% formalin solution. Three replicates, spaced approximately 7-10 meters apart, were made in each field, at least 10 meters from the field edge (Table 1).

\subsubsection{Samplings with commercial mustard}

We use the procedure proposed by the French participatory method of earthworm sampling (http://observatoire-agricolebiodiversite.fr/sites/oab.mnhn.fr/files/upload/attached/oab_guide_utilisateur_2013_protocolevers-de-terre.pdf). After removing vegetation present at the ground surface, two applications of $10 \mathrm{~L}$ of a mustard solution were applied to the soil $15 \mathrm{~min}$ apart over $1 \mathrm{~m}^{2}$. A suspension in water was prepared by mixing two $150 \mathrm{~g}$ jars of commercial hot mustard (Amora ${ }^{\circledR}$ 'Fine et Forte') in $10 \mathrm{~L}$ of water. All jars were from the same batch and had the same expiry date. A watering can with a rose was used to spread the solution evenly over the sampling surface. Emerging individuals were collected for $30 \mathrm{~min}$ and preserved in $4 \%$ formalin solution. Three replicates, spaced approximately 7-10 meters apart, were made in each field, at least 10 meters from the field edge (Table 1).

\subsubsection{Earthworm identification}

All individuals (juveniles, sub-adults and adults) were counted and weighed with their gut content. Sub-adults and adults were identified at species level according to the identification key of Sims and Gerard (1999). Juveniles were attributed to species according 
to morphological characteristics and to the specific form they take in formalin in comparison with that of identified adults.

\subsection{Statistical Analysis}

Observations were first transformed to record earthworm abundance and biomass per square meter. Medians of the three replicates per field were calculated and used for statistical analysis. Data presented in the results section are means of these medians. AITC concentration of irritating chemical as well as earthworm diversity (species richness), abundance and biomass in each field recorded with the different chemicals were compared with Wilcoxon Mann-Whitney non-parametric tests because conditions for parametric tests were not fulfilled. We used the R software (R Development Core Team, 2005).

\section{Results}

\section{1. Comparison of AITC concentrations}

Chemical analysis of the ten jars of commercial hot mustard from the same batch revealed that concentrations of AITC were relatively uniform within the same batch. The mean of the 10 jars was $860 \mu \mathrm{g} \cdot \mathrm{g}^{-1}$ with a standard deviation of $39 \mu \mathrm{g} \cdot \mathrm{g}^{-1}$, corresponding to a $5 \%$ standard deviation. Values ranged from 811 to $922 \mu \mathrm{g} \cdot \mathrm{g}^{-1}$.

For the 10 jars from different batches, AITC concentrations differed considerably between jars, with a standard deviation of $36 \%$. Values ranged from $273 \pm 11$ to $1306 \pm 13$ $\mu \mathrm{g} \cdot \mathrm{g}^{-1}$ (mean \pm standard deviation). We noticed that the concentration of AITC in the jars was higher when the indicated time before expiry of the mustard was longer (Fig. 1).

For the sampling with pure AITC (proposed by Zaborski, 2003 and Pelosi et al., 2009), $1 \mathrm{~mL}$ AITC was poured into $10 \mathrm{~L}$ of water. Since the density of the AITC was $1 \mathrm{~g} . \mathrm{cm}^{-}$ ${ }^{3}$, then $1 \mathrm{~mL}$ of AITC diluted in $10 \mathrm{~L}$ of water corresponded to a concentration of $0.1 \mathrm{~g} \cdot \mathrm{L}^{-1}$. 
For the sampling with commercial mustard (http://observatoire-agricolebiodiversite.fr/sites/oab.mnhn.fr/files/upload/attached/oab_guide_utilisateur_2013_protocolevers-de-terre.pdf) involving two $150 \mathrm{~g}$ jars of mustard diluted in $10 \mathrm{~L}$ of water, the average concentration of AITC was approximately $0.025 \mathrm{~g} . \mathrm{L}^{-1}$ in the solution that was spread on the soil. However, this concentration could vary from 0.008 to 0.039 g. $\mathrm{L}^{-1}$ according to the analysis of ten jars of different batches with 171 to 305 days before expiry. The AITC solution, used in the scientific method of earthworm sampling, was thus about four times more concentrated in AITC than the mean of commercial mustard solutions used in the participatory method.

\section{2. Comparison of chemical expellant efficiency}

Mean abundances of total expelled earthworms over the 22 fields were 6.1 and 14.5 individuals per $\mathrm{m}^{2}$ for mustard and AITC solutions respectively, but the difference was not significant ( $\mathrm{p}=0.39)$ (Fig. 2a). Most values obtained with the AITC solution were higher than with the mustard solution but their variability was also higher (Fig. 2a). Mean biomasses of the total earthworm community over the 22 fields were 1.9 g.m $\mathrm{m}^{-2}$ and 4.9 g.m $\mathrm{m}^{-2}$ for mustard and AITC solutions, respectively. Again, this difference was not significant $(\mathrm{p}=0.18)$ (Fig. 2b).

Both chemical expellants allowed us to sample seven species of earthworms. Six species were common to mustard and AITC solutions: Lumbricus terrestris (Linnaeus, 1758), Aporrectodea longa (Ude, 1885), Aporrectodea giardi (Ribaucourt, 1901), Allolobophora chlorotica (Savigny, 1826), Aporrectodea rosea (Savigny, 1826) and Aporrectodea caliginosa (Savigny, 1826) (Fig. 3). The first three are anecic and the last three are endogeic species. Aporrectodea icterica (Savigny, 1826), an endogeic species, was only found with the AITC solution and Lumbricus castaneus (Savigny, 1826), an epigeic species, was only found 
with the mustard solution (Fig. 3). AITC appeared to be more efficient than mustard to bring the three dominant species to the soil surface (Fig. 3): for mustard and AITC solutions, $L$. terrestris represented 21 and $27 \%$ of the total abundance, A. caliginosa represented 24 and 43\% of the total abundance and A. chlorotica represented 27 and 20\% of the total abundance, respectively.

\section{Discussion}

This study highlighted that AITC concentration was uniform among different jars of a given batch of commercial hot mustard (Amora ${ }^{\circledR}$ 'Fine et Forte'), used in the participatory method for earthworm sampling and exported and therefore available worldwide. However, the AITC concentration in mustard jars varied five-fold, depending on their use by date. This can cause problems of standardization of the method since commercial mustards of the same brand may not have the same efficiency. Efficiency does not necessarily increase with AITC concentration (Čoja et al., 2008) but the concentration found in the mustard solution was low compared to the optimal AITC concentrations reported by Zaborski (2003). It is thus preferable to use jars with a long time before expiry. To get reliable and comparable results between fields in a study, it is thus preferable to use mustard jars (i) with a long time before expiry for maximum efficiency and (ii) from the same batch for minimum variation in expellant efficiency.

Abundance of extracted individuals was quite low compared to data reported by Čoja et al. (2008) in a meadow or by Pelosi et al. (2009) in cultivated fields. This may be due first to the ploughing of the fields where earthworms were collected: in ploughed fields, endogeics are generally found in majority compared to anecics (Chan, 2001), while chemical expellants are preferentially used to collect the latter ecological group (Bouché, 1972). Secondly, the soil was perhaps slightly too dry for an optimal penetration of chemicals in soil. However, it could 
have been unnecessary to add water before doing the samples, since Eisenhauer et al., 2008 explained that "surprisingly, the efficiency [...] was not improved by beforehand water addition". The results might have been different if the soil had been wetter. Nevertheless, the values found in this study are in accordance with the data published by Bartlett et al (2006) for mustard. Moreover, a hand sorting of earthworms at the end of the extraction time revealed that individuals were active (i.e. not curled in an inactive stage).

Both expellant solutions used the same compound, AITC, to extract earthworms but in one case it was pure and in the other case, it was only a component of a commercial product. Although (i) a greater quantity of chemical is sprayed on the soil per square meter (Table 1) and (ii) the concentration of AITC was four times higher in the AITC solution, both solutions seemed to have almost the same efficiency to bring earthworms to the soil surface. While both expellant solutions retrieved the same number of species, we found a trend towards collecting more individuals of the three dominant species with the AITC solution. This could be due either to the more irritating character of the solution, given the difference in AITC concentration, or to the pure compound being more evenly spread in the water, thanks to early isopropanol dilution (Pelosi et al., 2009; Zaborsky, 2003). Indeed, in the field, it was necessary to mix the mustard very thoroughly in water before application to prepare an adequate suspension of commercial mustard. Finally, commercial mustard's components, other than AITC, may have participated to the efficiency of this expellant for earthworms.

We here compared advantages and drawbacks of two extraction methods that are currently used by scientists and citizens for earthworm sampling in France and elsewhere (Table 2). The area sampled with the mustard solution was 6.25 times larger than that sampled with AITC solution. Thus, the amount of material and water needed was proportionally higher. 


\section{Conclusion}

We here described a new effective method to measure allyl isothiocyanate concentration in mustard. Testing commercial mustard jars from different batches and jars from the same batch, we found that AITC concentration in mustard varied five-fold, depending on its use by date. The comparison of the AITC concentration in two earthworm expellant solutions (diluted commercial mustard and pure AITC solution, used in a French participatory method and a scientific method respectively), revealed that AITC concentration was about 4 times higher in the AITC solution than in the mustard one. Moreover, AITC and commercial mustard solutions had the same earthworm extracting efficiency.

To improve the efficiency of earthworm samplings with commercial mustard (as in participatory method), it is thus recommended to use jars of commercial hot mustard Amora ${ }^{\circledR}$ 'Fine et Forte' from the same batch and with a long time before expiry. It would also be useful to note the expiry date of jars used for earthworm sampling when using the participatory method.

\section{Acknowledgements}

We would like to thank everybody who participated in earthworm sampling and more especially Lucile Toutous, Jodie Thénard, Félix Fraillon, Françoise Elsass and Nathalie Cheviron. Financial support was provided by the 'Fédération Île-de-France de Recherche sur l'Environnement' (FIRE, FR3020) and the 'Agence Nationale pour la Nature et la Biodiversité en Île-de-France' (Natureparif). We would also like to thank Marjolaine Deschamps for initial informations on AITC analysis and Alan Scaife for revising the English.

\section{References}


Bartlett, M.D., Harris, J.A., James, I.T., Ritz, K., 2006. Inefficiency of mustard extraction technique for assessing size and structure of earthworm communities in UK pasture. Soil Biol. Biochem. 38, 2990-2992.

Bartlett, M.D., Briones, M.J.I., Neilson, R., Schmidt, O., Spurgeon, D., Creamer, R.E., 2010. A critical review of current methods in earthworm ecology: from individuals to populations. Eur. J. Soil Biol. 46, 67-73.

Bouché, M.B., 1972. Lombriciens de France: Ecologie et Systématique. INRA Ann Zool Ecol Anim Publication, Paris.

Chan, K.Y., 2001. An overview of some tillage impacts on earthworm population abundance and diversity - implications for functioning in soils. Soil Tillage Res. 57, 179-191.

Čoja, T., Zehetner, K., Bruckner, A., Watzinger, A., Meyer, E., 2008. Efficacy and side effects of five sampling methods for soil earthworms (Annelida, Lumbricidae). Ecotoxicol. Environ. Saf. 71, 552-565.

Edwards, C.A., Bohlen, P.J., 1996. Biology and Ecoloy of Earthworms, 3rd ed. Chapman and Hall, London.

Eisenhauer, N., Straube, D., Scheu, S., 2008. Efficiency of two widespread non-destructive extraction methods under dry soil conditions for different ecological earthworm groups. Eur. J. Soil Biol. 44, 141-145.

Evans, A.C., McL. Guild, W.J., 1948. Studies on the relationships between earthworms and soil fertility. Ann. Appl. Biol. 35, 485-493.

Hils, A.K.A., Verlomme-Fried, A., Höfler, N., 2001. Bestimmung von Allylisothiocyanat in Speisesenfen und Meerrettichzubereitungen. Z. Arzn. Gew. Pfl. 6, 25-28.

Högger, C.H., 1993. Mustard flour instead of formalin for the extraction of earthworms in the field. Bull. Bodenkundl. Gesellsch. Schweiz. 17, 5-8. 
ISO 23611-1:2006. Soil quality - Sampling of soil invertebrates - Part 1: Hand-sorting and formalin extraction of earthworms.

Lawrence, A.P., Bowers, M.A., 2002. A test of the "hot" mustard extraction method of sampling earthworms. Soil Biol. Biochem. 34, 549-552.

Muramoto, J., Werner, M.R., 2002. Mustard powder vermifuge: an alternative to formalin expulsion method for earthworm sampling. Edaphologia 70, 7-11.

Oberholzer, H.R., Knuchel, R.F., Weisskopf, P., Gaillard, G., 2012. A novel method for soil quality in life cycle assessment using several soil indicators. Agron. Sustain. Dev. 32, 639649.

Paoletti, M.G., 1999. The role of earthworms for assessment of sustainability and as bioindicators. Agr. Ecosyst. Environ. 74, 137-155.

Pelosi, C., Bertrand, M., Capowiez, Y., Boizard, H., Roger-Estrade, J., 2009. Earthworm collection from agricultural fields: comparisons of selected expellants in presence/absence of hand-sorting. Eur. J. Soil Biol. 45, 176-183.

R Development Core Team (2005). R: A Language and Environment for Statistical Computing. R Foundation for Statistical Computing, Vienna, Austria.

Raw, F., 1959. Estimating earthworm population by using formaline. Nature 184, 1661-1662. Sims, R.W., Gerard, B.M., 1999. Earthworms. FSC Publications, London.

Valckx, J., Govers, G., Hermy, M., Muys, B., 2011. Optimizing earthworm sampling in ecosystems, in: Karaca, A. (Eds.), Biology of Earthworms. Springer, Berlin, pp. 19-38.

Zaborski, E.R., 2003. Allyl isothiocyanate: an alternative chemical expellant for sampling earthworms. Appl. Soil Ecol. 22, 87-95. 
Table 1. Characteristics of the two earthworm sampling methods.

\begin{tabular}{lll} 
& Sampling with AITC & Sampling with commercial mustard \\
\hline Sample size & $40 \times 40 \mathrm{~cm} \times 20 \mathrm{~cm} \mathrm{depth}$ & $100 \times 100 \mathrm{~cm}$ \\
Number of replicates & 3 & 3 \\
Distance between replicates & $7-10 \mathrm{~m}$ & $7-10 \mathrm{~m}$ \\
Chemical expellant & AITC with isopropanol $\left(5 \mathrm{~g} . \mathrm{L}^{-1}\right)$, diluted with & 2 jars of $150 \mathrm{~g}$ of commercial hot mustard \\
& water $\left(0.1 \mathrm{~g} . \mathrm{L}^{-1} \mathrm{AITC}\right)$ & Amora ${ }^{\circledR}$ 'Fine et Forte' in $101 \mathrm{of}$ water \\
Quantity of chemical applied to the soil & 2 applications of $3.2 \mathrm{~L}$ at 10-min interval & 2 applications of $10 \mathrm{~L}$ at 15 -min interval \\
Quantity of chemical applied to the soil per $\mathrm{m}^{-2}$ & $40 \mathrm{~L}$ & $20 \mathrm{~L}$ \\
Collection duration & $20 \mathrm{~min}$ & $30 \mathrm{~min}$ \\
\hline
\end{tabular}

3

AITC with isopropanol $\left(5\right.$ g.L $\left.\mathrm{L}^{-1}\right)$, diluted with water $\left(0.1\right.$ g.L. ${ }^{-1}$ AITC)

2 applications of $3.2 \mathrm{~L}$ at 10 -min interval

$20 \mathrm{~min}$
Sampling with commercial mustard

3

7-10 m

2 jars of $150 \mathrm{~g}$ of commercial hot mustard

2 applications of $10 \mathrm{~L}$ at 15 -min interval 
Table 2. Comparison of earthworm sampling using AITC or commercial mustard solutions

\begin{tabular}{lll}
\cline { 2 - 3 } Principle of the method & Sampling with AITC & Sampling with commercial mustard \\
\hline Safety for handlers & AITC (with isopropanol) solution & Commercial hot mustard solution \\
& $\begin{array}{l}\text { Pre-preparation (AITC and isopropanol) in the lab } \\
\text { (pure AITC is highly volatile, risk of burning } \\
\text { because of high concentration) and dilution in } \\
\text { water in the field }\end{array}$ & Can be prepared in the field, safety for handlers \\
\hline Safety for environnement & $\begin{array}{l}\text { Same expellant molecule (allyl isothyocianate) } \\
\text { Additives: isopropanol }\end{array}$ & $\begin{array}{l}\text { Same expellant molecule (allyl isothyocianate) } \\
\text { Additives: manufacturer' trade secret }\end{array}$ \\
\hline Easy access to chemical expellants & Bought from a supplier & Available in many shops, exported worldwide \\
\hline Amount of water to be transported in the field & 6.4 L per replicate & 20 L per replicate \\
\hline Time needed & Approximately 35 min per person per replicate & Approximately 50 min per person per replicate \\
\hline
\end{tabular}


Fig. 1.

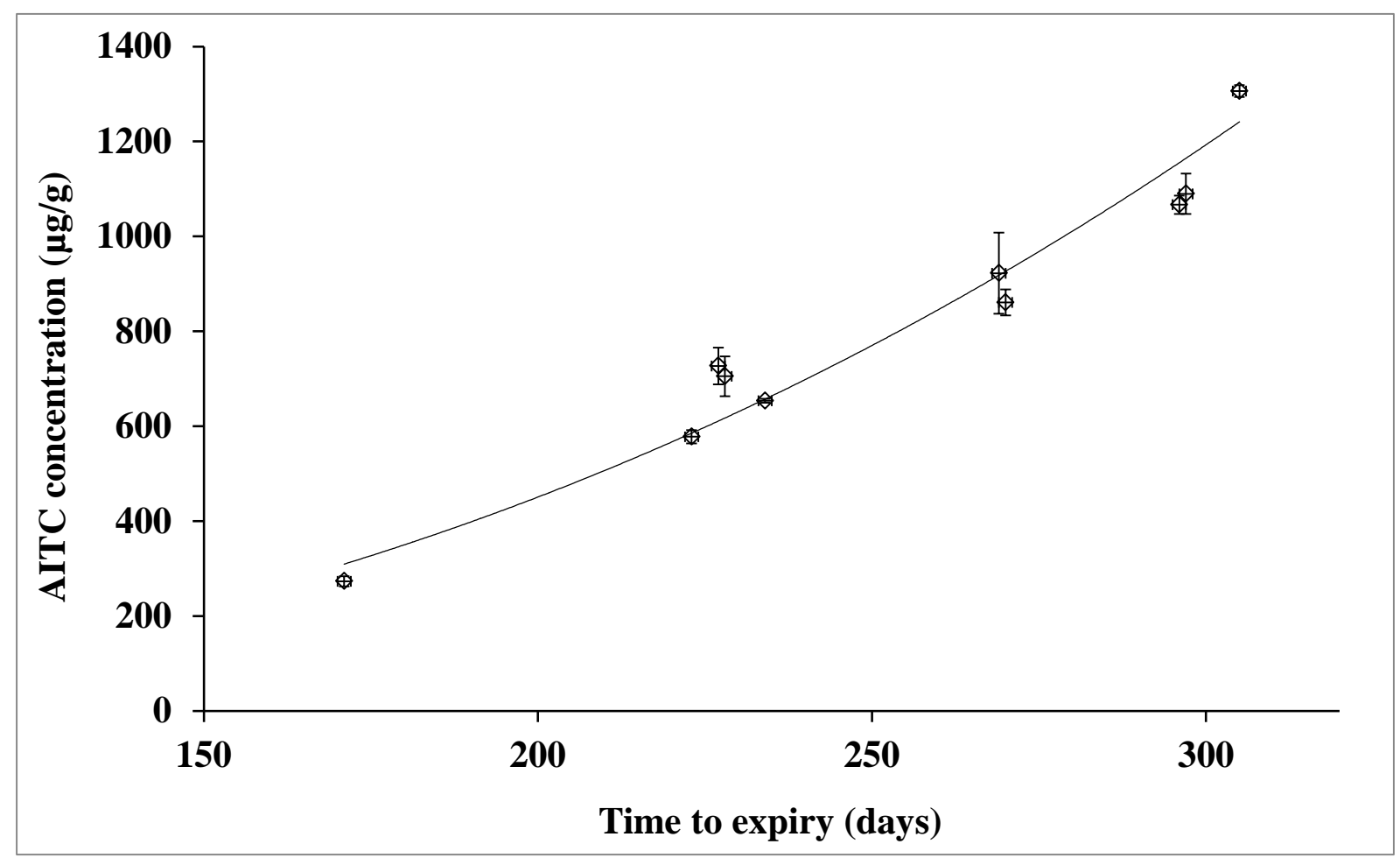

Fig. 1. Allylisothiocyanate concentration evaluated as a function of mustard time to expiry (mean of triplicate analyses; error bars correspond to standard deviation). 
Fig. 2.
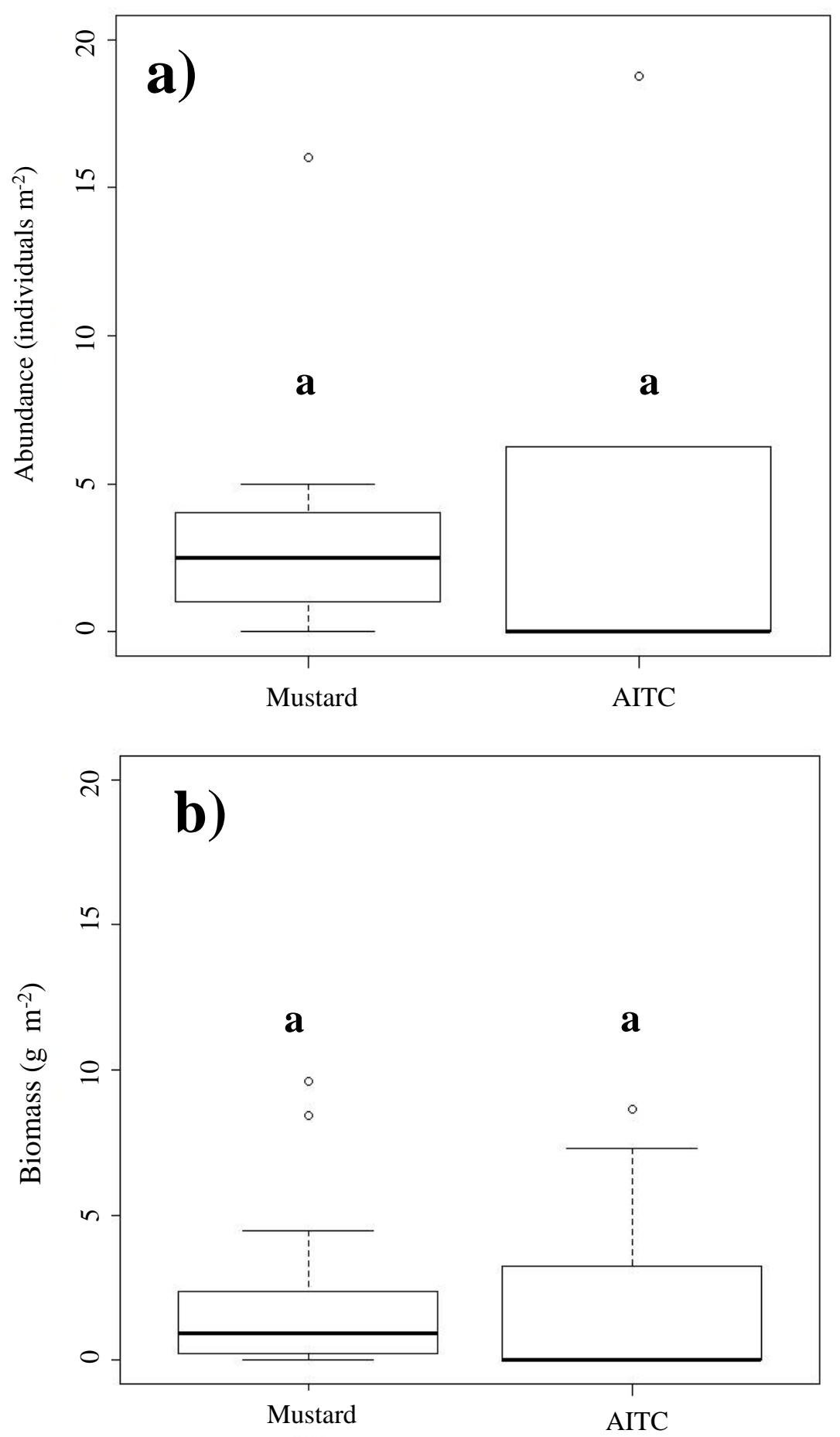

Fig. 2. Boxplots of earthworm abundance (a) and biomass (b) for commercial mustard and AITC solutions. Boxes with the same letter are not different at $P=0.05$. Values higher than 20 individuals $\mathrm{m}^{-2}$ for abundance (three values for mustard and three values for AITC) and 20 $\mathrm{g} \mathrm{m}^{-2}$ for biomass (one value for AITC) are not represented. 
Fig. 3.

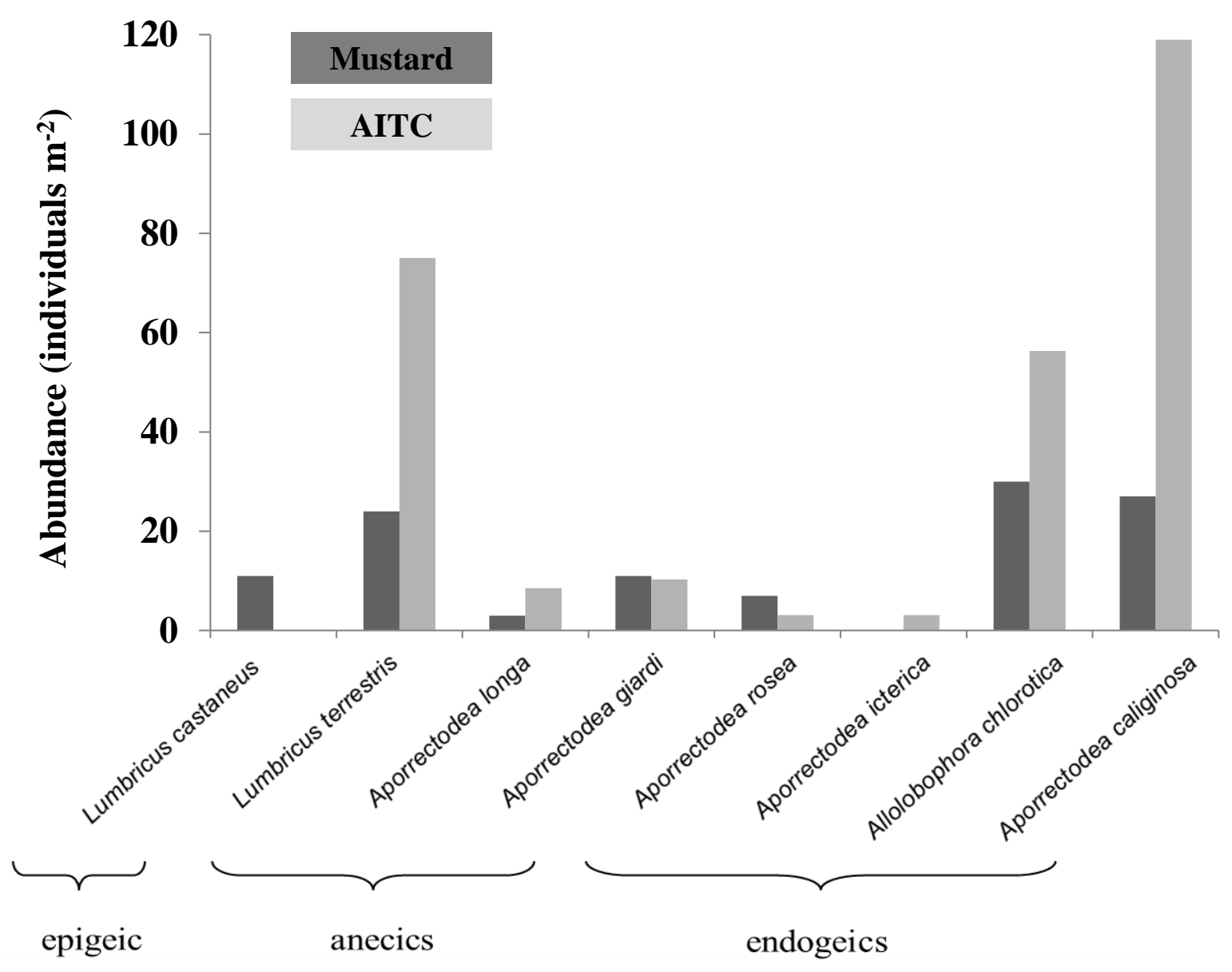

Fig. 3. Cumulative abundance (earthworms $\mathrm{m}^{-2}$ ) of the species found in the 22 agricultural fields for commercial mustard and AITC solutions. 
1 Appendix A. Site and soil characteristics of the 22 sampled agricultural field plots in Seine-et-

2 Marne (all under winter wheat).

\begin{tabular}{|c|c|c|c|c|c|c|c|c|c|}
\hline Plot name & GPS Coordinates & Cropping system & Clay $\left(\mathrm{g} \mathrm{kg}^{-1}\right)$ & Silt $\left(\mathrm{g} \mathrm{kg}^{-1}\right)$ & Sand $\left(\mathrm{g} \mathrm{kg}^{-1}\right)$ & Organic matter $\left(\mathrm{g} \mathrm{kg}^{-1}\right)$ & $\mathrm{CaCO} 3\left(\mathrm{~g} \mathrm{~kg}^{-1}\right)$ & $\mathrm{C} / \mathrm{N}$ ratio & $\mathrm{pH}$ \\
\hline Org1 & N 4879,909' E $3^{\circ} 13,267^{\prime}$ & Organic & 261.0 & 646.0 & 26.0 & 19.3 & 1.0 & 10.2 & 7.4 \\
\hline Org2 & N 4866,961' E 3¹7,820' & Organic & 242.0 & 696.0 & 16.0 & 19.5 & 1.0 & 9.8 & 7.8 \\
\hline Org3 & N 4867,099' E $3^{\circ} 17,904^{\prime}$ & Organic & 299.0 & 653.0 & 12.0 & 19.5 & 1.0 & 9.8 & 7.5 \\
\hline Org4 & N 4868,602' E $2^{\circ} 78,570^{\prime}$ & Organic & 174.0 & 664.0 & 65.0 & 22.7 & 1.0 & 11.9 & 7.8 \\
\hline Org5 & N 4843,157' E $3^{\circ} 32,136^{\prime}$ & Organic & 193.0 & 284.0 & 77.0 & 25.7 & 1.0 & 11.2 & 8.5 \\
\hline Org6 & N 4870,640' E $2^{\circ} 67,897^{\prime}$ & Organic & 178.0 & 733.0 & 33.0 & 32.7 & 1.0 & 13.6 & 7.3 \\
\hline Org7 & N 4876,876' E $3^{\circ} 15,272^{\prime}$ & Organic & 194.0 & 751.0 & 25.0 & 23.2 & 1.0 & 10.8 & 7.5 \\
\hline Org8 & N 4876,566' E $3^{\circ} 14,826^{\prime}$ & Organic & 170.0 & 765.0 & 32.0 & 19.5 & 1.0 & 10.7 & 7.5 \\
\hline Org9 & N 4864,506' E $3^{\circ} 04,909^{\prime}$ & Organic & 227.0 & 689.0 & 19.0 & 23.7 & 1.1 & 10.0 & 7.6 \\
\hline Org10 & N 4829,850' E 287,968' & Organic & 256.0 & 347.0 & 175.0 & 26.0 & 1.7 & 11.6 & 7.6 \\
\hline Org11 & N 4884,641' E $3^{\circ} 10,906^{\prime}$ & Organic & 165.0 & 774.0 & 24.0 & 19.0 & 1.0 & 10.7 & 7.9 \\
\hline Conv1 & N 4861,808' E 296,832' & Conventional & 204.0 & 704.0 & 28.0 & 18.1 & 1.0 & 9.9 & 7.9 \\
\hline Conv2 & N 4903,467' E 284,154' & Conventional & 213.0 & 723.0 & 12.0 & 18.2 & 5.5 & 9.9 & 8.1 \\
\hline Conv3 & N 4906,166' E 294,686' & Conventional & 180.0 & 756.0 & 10.0 & 16.9 & 1.1 & 9.9 & 7.9 \\
\hline Conv4 & N 4845,583' E $3^{\circ} 14,232^{\prime}$ & Conventional & 221.0 & 658.0 & 43.0 & 20.7 & 7.9 & 9.9 & 8.3 \\
\hline Conv5 & N 4843,775' E $3^{\circ} 04,751^{\prime}$ & Conventional & 160.0 & 580.0 & 135.0 & 16.1 & 1.0 & 10.5 & 6.4 \\
\hline Conv6 & N 4850,036' E $3^{\circ} 12,826^{\prime}$ & Conventional & 228.0 & 667.0 & 25.0 & 16.0 & 1.0 & 9.9 & 8.2 \\
\hline Conv7 & N 4902,709' E $2^{\circ} 98,335^{\prime}$ & Conventional & 298.0 & 648.0 & 7.0 & 17.6 & 1.0 & 9.4 & 7.4 \\
\hline Conv8 & N 4840,579' E 3³2,293' & Conventional & 270.0 & 457.0 & 123.0 & 26.9 & 7.5 & 10.9 & 8.2 \\
\hline Conv9 & N 4879,928' E $3^{\circ} 13,529^{\prime}$ & Conventional & 209.0 & 692.0 & 23.0 & 17.3 & 1.0 & 10.4 & 7.2 \\
\hline Conv10 & N 4868,684' E $2^{\circ} 78,558^{\prime}$ & Conventional & 197.0 & 646.0 & 55.0 & 18.3 & 1.0 & 10.2 & 7.1 \\
\hline Conv11 & N 48 $84,380^{\prime}$ E $3^{\circ} 10,896^{\prime}$ & Conventional & 244.0 & 662.0 & 41.0 & 23.8 & 5.9 & 10.4 & 8.0 \\
\hline
\end{tabular}

4 